\title{
Protective effects of intravenous lipid emulsion on malathion-induced hepatotoxicity
}

\author{
Esen $\mathrm{M}^{1}$, Uysal $\mathrm{M}^{2}$ \\ Gaziosmanpasa University, Faculty of Medicine, Department of Emergency Medicine, \\ Tokat, Turkey.dr_mesen@hotmail.com
}

\section{ABSTRACT}

OBJECTIVE: Organophosphates including malathion can be ingested, inhaled, or absorbed through the skin, but it may be a maximum of acute toxicity when administered by oral intake. Intravenous lipid emulsion (ILE) treatment is used as a new treatment method in cases of systemic toxicity caused by local anesthetics. This study was aimed to examine the potential treatment effect of intravenous lipid emulsion on rat liver tissue in the toxicity of malathion.

METHODS: Twenty-one Wistar albino rats were randomly divided into three equal groups. The groups were organized as Group I (control), Group II (malathion) and Group III (malathion + lipid emulsion treatment). Liver tissues were examined histologically, and immunohistochemical analysis was performed to determine the bax, bcl-2, and caspase-3 expression levels.

RESULTS: A decrease of PAS positive staining cells, and an increase of liver enzymes, formation of degenerative changes and apoptotic cell deaths occurred in the malathion group. Additionally, a decrease of apoptosis and hepatic parenchymal damage was observed in the malathion + lipid emulsion treatment group.

CONCLUSION: The findings from our study suggested that lipid emulsion treatment had a protective efficacy on the malathion induced liver toxicity (Fig. 5, Ref. 30). Text in PDF www.elis.sk

KEY WORDS: malathion, toxicity, intravenous lipid emulsion, apoptosis, liver.

\section{Introduction}

Organophosphates are pesticides with high toxicity levels that are easily accessible and widely used in agriculture (1). Poisonings due to organophosphates hold an important place among patients admitted to emergency services. While acute organophosphate poisonings occur mostly orally, it can also occur through skin and inhalation (2). The basic principle of symptomatic treatment is to inhibit acetyl cholinesterase (3). Despite anticholinergic treatment and sophisticated intensive care facilities, severe organophosphate (OP) poisoning has a high ( $\sim 30-40 \%)$ mortality rate (4). Therefore, a better understanding of pathophysiology caused by OPs and the development of new treatment modalities are of great importance in OP toxicity.

The intravenous lipid emulsion (ILE) therapies are currently being used as a new treatment method in case of systemic toxicity caused by local anesthetic therapies (5). Experimental studies showed that ILE therapy is effective in the treatment of cardiac arrest and cardiovascular collapse induced by bupivacaine and levobupivacaine toxicity $(6,7)$.

${ }^{1}$ Gaziosmanpasa University, Faculty of Medicine, Department of Emergency Medicine, Tokat, Turkey, and ${ }^{2}$ Gaziosmanpasa University, Faculty of Medicine, Department of Anatomy, Tokat, Turkey

Address for correspondence: M. Esen, MD, Gaziosmanpasa University, Faculty of Medicine, Department of Emergency Medicine, Tokat, Turkey Phone: +90 35621494 44, Fax: +90 3562149777
Organophosphate poisoning was reported to cause damage on several tissues such as: liver, kidney, pancreas and brain (8-10). In experimental studies conducted to reduce this damage, antioxidants were mentioned to have a protective effect $(11,12)$. Recently, therapeutic effect of lipid emulsion therapy on toxic effects of organophosphate was suggested as a hypothesis $(13,14)$. Effects of lipid emulsion therapy on pancreas, ovarium and brain damage caused by malathion, which is also an organophosphate, were examined (15-17). However, we did not come across any studies examining its specific effects on liver. Thus, our study was aimed to examine therapeutic effect of intravenous lipid emulsion therapy (20\% lipid solution), in the intoxication model formed with malathion, on liver tissue.

\section{Materials and methods}

\section{Animal selection}

This study was conducted with a permission of the Local Ethics Committee (2014 HADYEK-74). In the experiment, 21 Wistar albino male rats weighing 200-250 g. were used. Experimental applications in the research were carried out in accordance with the regulations for the care and use of laboratory animals.

\section{Experimental procedure}

Rats were divided into three equal groups, each containing 7 rats; Group I (control), Group II (malathion) and Group III (malathion + intravenous lipid therapy). The Group II was 
given $100 \mathrm{mg} / \mathrm{kg}$ malathion (Malathion $\mathrm{EM}^{\circledR}$, Tarkim, Kocaeli, Turkey) by a gavage route. The dose of malathion was calculated based on LD50 and body weight (LD50 for male Wistar albino rat: $1768-1857 \mathrm{mg} / \mathrm{kg}$ ). The Group III was administered, in addition to malathion after 10 minutes, $20 \%$ lipid solution (OliClinomel N7-1000 E ${ }^{\circledR}$, Eczacibas1-Baxter, Istanbul, Turkey) as $3 \mathrm{ml} / \mathrm{kg}$ with a branule connected to tail vein. Animals in the control group were administered only $1 \mathrm{~mL}$ of corn oil by gavage route and $3 \mathrm{~mL} / \mathrm{kg}$ saline by intravenous cannula. Rats were killed by decapitation under $50 \mathrm{mg} / \mathrm{kg}$ intraperitoneal (i.p.) ketamine hydrochloride (Ketalar ${ }^{\circledR}$, Eczacibası, Istanbul, Turkey) anesthesia plus $5 \mathrm{mg} / \mathrm{kg}$ i.p. xylazine (Rompun ${ }^{\circledR}$, Bayer, Leverkusen, Germany) $12 \mathrm{~h}$ after the gavage administration. At the end of the procedure, liver tissues were surgically removed for histological examination.

\section{Histological examination}

The liver tissues were removed and kept in $10 \%$ formalin solution. After routine histologic follow-ups, they were embedded into paraffin. 4-5 $\mu \mathrm{m}$ thick sections were taken from paraffin-embedded tissues and stained with Hematoxylin-Eosin (H\&E) and Periodic Acid Schiff (PAS) method. The stained sections were examined under a Zeiss Axio Lab A1 light microscope. H\&E-stained sections were used for histological examination of the tissue. To identify glycogen, liver tissue sections were stained with Periodic Acid
Schiff (PAS kit; Hotchkiss Mc Manus, 04-130802, Bio-Optica, Milano, Italy). Evaluation of the glycogen levels were performed using image processing software (Image J 1.50) as previously described (18). Integrated densities obtained by ImageJ were taken as an indication of glycogen levels. Four randomly selected areas were evaluated for each slide (40x objective) and the average values were used.

\section{Immunohistochemistry}

Immunohistochemistry was performed according to previously described procedures (19). Briefly, $5 \mu \mathrm{m}$ serial sections were collected on poly-L-lysine coated slides, and they were deparaffinized in xylene and rehydrated in a graded series of ethanol. Then, sections were treated in a microwave oven in $10 \mathrm{mM}$ citrate buffer ( $\mathrm{pH}$ 6.0) for antigen retrieval. To prevent base staining, sections were incubated in a blocking serum (Ultra V Block, ScyTek Laboratories, Utah, USA), it was incubated with primer antibodies (rabbit polyclonal active-Caspase 3, ab13847, Abcam, UK; rabbit polyclonal anti-Bax; ab7977, Abcam, Germany; and rabbit polyclonal anti-Bcl-2, ab7973, Abcam, UK). After the primary antibody application, second antibody (ScyTek Laboratories, Utah, USA) was applied, and 3-Amino-9-ethyl carbazole (AEC) chromogen was performed. The sections were counterstained with Mayer's hematoxylin (ScyTek Laboratories), and then they were mounted with Permount (Fisher Chemicals, Springfield, NJ, USA)
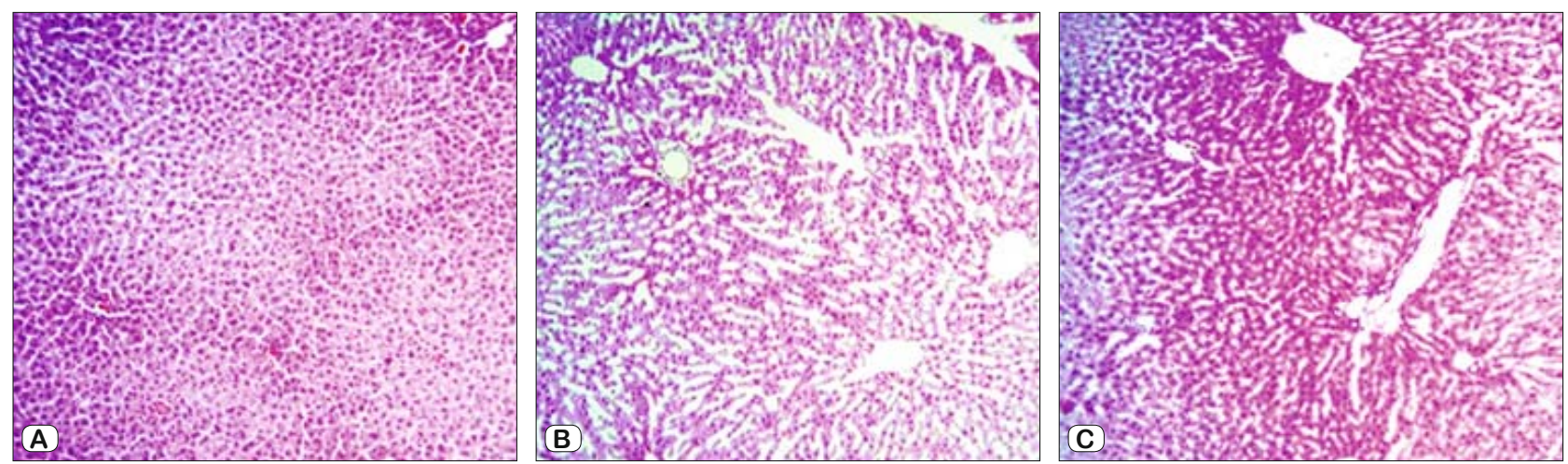

Fig. 1. Liver tissue sections stained with hematoxylin-eozin (H\&E); (A) Control group, (B) Malathion group, (C) Malathion+ILE group (x10 objective).
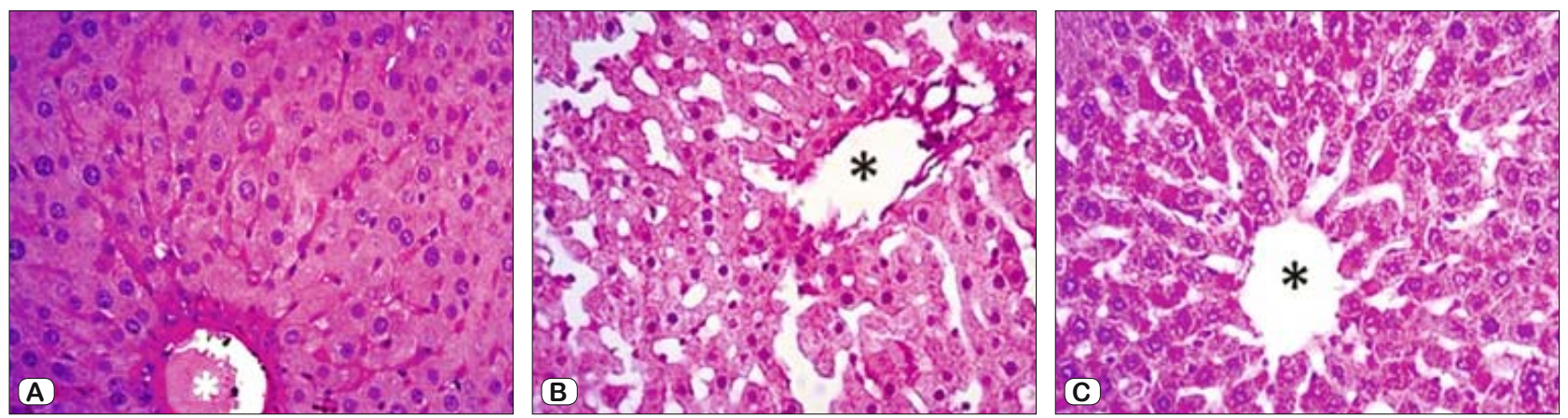

Fig. 2. Representative appearances of liver tissue specimens after PAS staining; (A) Control group, (B) Malathion group, (C) Malathion+ILE group. *Denotes central vein in the liver (x40 objective). 
on glass slides. For negative controls, sections were treated with normal rabbit serum. Photomicrographs were taken with a Leica microscope (Leica DM2500, Nussloch, Germany).

\section{Evaluation of immunohistochemistry}

Evaluation of the immunohistochemical labeling was performed using H-SCORE analyses as previously described (19). The liver of the Caspase3, Bax and Bcl-2 immunoreactivities were semi-quantitatively evaluated using the following categories: 0 (no staining), 1+ (weak but detectable staining), 2+ (moderate or distinct staining), and $3+$ (intense staining). For each tissue, an H-SCORE value was derived as followed. First, the sum of the percentages of cells stained at each intensity category was calculated, and then, that value was multiplied by the weighted intensity of the staining using the formula as followed: H-SCORE = $\sum \mathrm{Pi}(\mathrm{i}+1)$. In this formula, 'i' represents the intensity scores, and ' $\mathrm{Pi}$ ' is the corresponding percentage of the cells. Five randomly selected areas were evaluated under a light microscope on each slide (40x objective).

\section{Statistical analysis}

Statistical analyzes were performed using the IBM-SPSS 20 program. One-way ANOVA test was used for comparing groups in terms of integrated density and $\mathrm{H}$-score values, and Tukey test was used as post-hoc test. $\mathrm{p}<0.05$ was considered statistically significant.

\section{Results}

\section{Histopathologic results}

In malathion administered rats, regular arrangement of hepatocytes was distorted, sinusoidal expansion appeared, and ballooning degeneration was developed. There was also focal mononuclear cell infiltration in parenchyma. However, in the group treated with lipid therapy, cellular damage was reduced and hepatocytes were more regularly arranged alongside the sinusoid (Fig. 1).

The liver tissue sections were stained with PAS for the evaluation of glycogen content (Fig. 2), and integrated density results were shown in Figure 3. In the malathion group, the integrat-

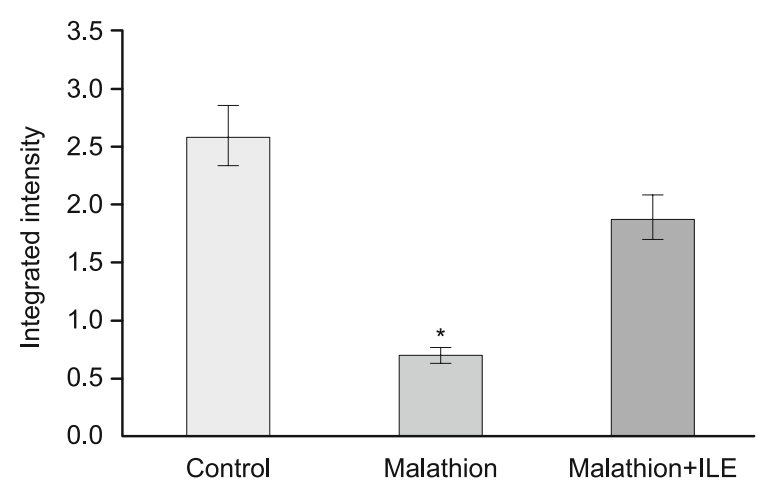

Fig. 3. Integrated intensity values of PAS staining. * $p<0.01$, compared to the control and Malathion+ILE group. ed density value was significantly lower in comparison to the malathion+ILE and the control group $(\mathrm{p}<0.01)$ (Fig. 3). Additionally, malathion-administered rats had a decreased PAS positivity, and the rats exposed to malathion along with ILE treatment had an increased PAS positivity (Fig. 2).

\section{Immunohistochemical results}

The liver tissue sections bax, bcl-2 and caspase-3 proteins were dyed immunohistochemically (Fig. 4). H-score results were evaluated and shown in Figure 5. The bax, bcl-2 and caspase-3 immunoreactivity in malathion group was significantly increased $(\mathrm{p}<0.001)$, and the immunoreactivity of all three proteins was lower in the malathion+ILE group compared to the malathion group $(\mathrm{p}<0.01)$ (Fig. 5).

\section{Discussion}

Organophosphate (OP) insecticides inactivate cholinesterase enzyme by phosphorylating them. Thus, the increased acetylcholine constantly stimulates cholinergic receptors. OPs can also lead to metabolic disorders and organ damage. Organophosphate compounds can induce oxidative stress in the hepatocellular mitochondria, the primary production site of reactive oxygen species (ROS) in liver cell. ROS production might cause cell damage by failure in mitochondrial function due to an increase in membrane permeability $(20,21)$. It was reported that this cell damage caused by organophosphate poisonings takes place in many tissues such as: liver, kidney, pancreas and brain (8-10).

Malathion, widely used organophosphate with high toxicity, cause hepatocellular damage in liver tissue and increase liver enzyme activity (22). Previous study claimed that OPs increased the apoptotic activity by causing mitochondrial injury in the tissue. The mitochondrial injury causes damaged oxidative pathway and this situation may increase the use of glucose by the way of glycolysis $(23,24)$. Decreased PAS positivity as observed in our study may result from injured mitochondria and decreased glucose levels.

Exposure to acute organophosphate was shown to cause loss of hepatocytes by inducing apoptosis. In the study conducted by Kurtulus et al (25), it was shown that organophosphate exposure increased caspase 1, caspase 3 and p53 gene, and histopathological inflammation and pyknosis were observed in the portal area. In a study performed by Amal et al (26) on people with organophosphate exposure, it was revealed that true and pseudo cholinesterase levels and antioxidants (GSH) were decreased in people exposed to OP poisoning, while MDA and caspase-3 activity was increased. In our study, it was also observed that bax and caspase-3 activities were increased significantly in liver tissues of the rats exposed to organophosphate and this increase was assessed in favor of hepatocellular damage.

OPs increase oxidative stress in liver tissue and most likely lead to an increase in bax and caspase 3 immunoreactivity by activating the intrinsic pathway of apoptosis. In addition to oxidative damage, the inhibition of mitochondrial respiratory complexes by OPs may also be an additional intrinsic factor that triggers apoptosis (27). Intravenous lipid emulsion (ILE) has been widely used 

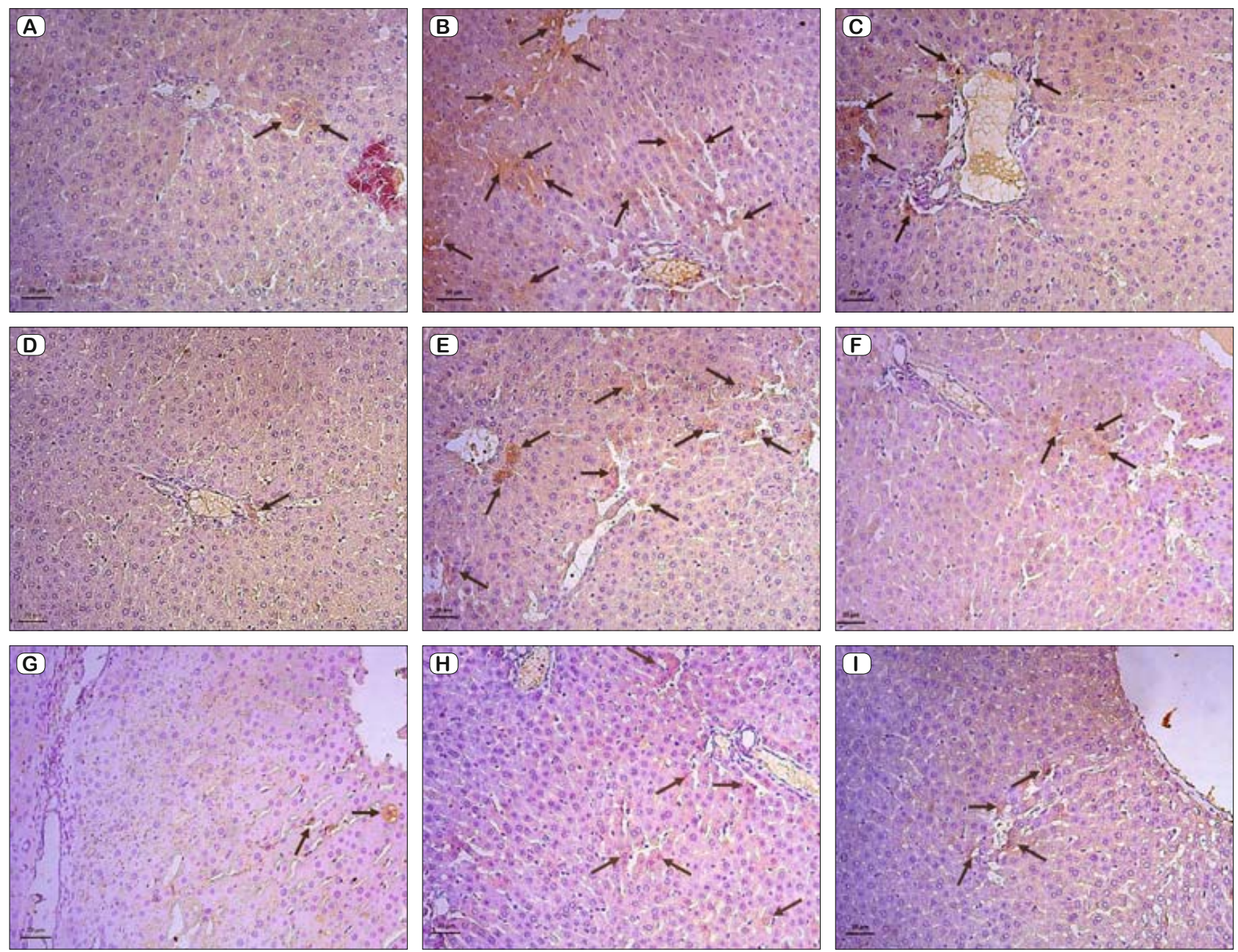

Fig. 4. Immunoreactivity of Caspase-3 (A, B, C), Bax (D, E, F) and Bcl-2 (G, H, I) in the liver tissues of all the groups. There was a high immunoreactivity for Caspase-3, Bax and Bcl-2 in the liver of malathion-treated rats $(\mathrm{B}, \mathrm{E}, \mathrm{H})$. Decreased immunoreactivity for Bax, Bcl-2 and Caspase-3 in the liver of malathion plus lipid treated rats (C, F, I). Very few Bax, Bcl-2 and Caspase-3 stained cells were observed in the control group (A, D, G) (x20 objective).

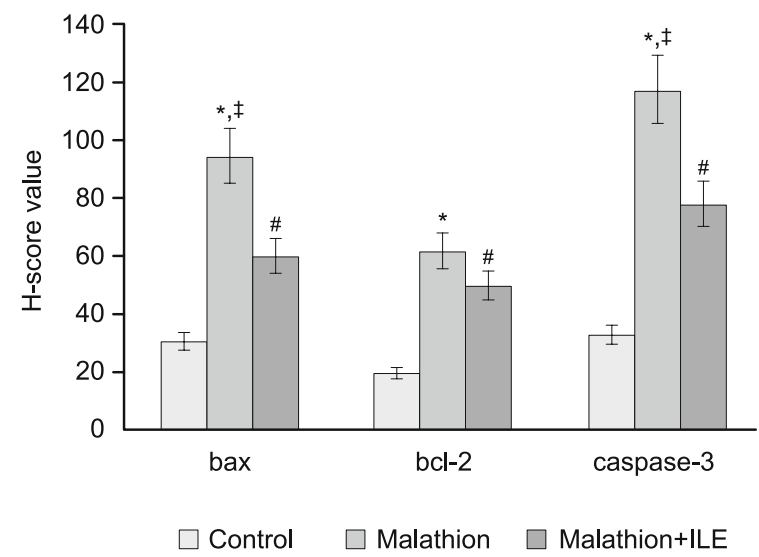

Fig. 5. H-score values of Bax, bcl-2 ve caspase-3 immunoreactivity. * $\mathrm{p}<0.001$, compared to the control group; $\$ \mathrm{p}<0.01$, compared with Malathion+ILE group; ${ }^{*} \mathbf{p}<0.01$, compared to the control group. in clinical practice as an energy substrate containing essential fatty acids (28). In our study, we found a decrease in apoptosis in liver tissue after treatment with ILE. The use of fatty acids contained within the ILE as a good source of energy might have provided a protective mechanism against apoptosis by further increasing the ATP levels in these cells. Additionally, increased glycogen levels and PAS positivity in the liver tissue that we detected in our study might be due to the energy supply effect of ILE.

Intravenous lipid emulsion (ILE) infusion is a new treatment modality used in lipophilic drug toxicity. The mechanism of action of lipid therapy is explained by a theory called "Lipid Sink". According to this theory, it is argued that lipid molecules forming complexes with lipophilic drugs imprison toxic agents and make them sink in the emulsion $(5,12)$. Zhou et al $(14)$ presented a two-step treatment protocol as a hypothesis in their study for organophosphate poisoning. They stated that they intended to reduce harmful effects of toxic substances by starting lipid treat- 
ment quickly and isolating toxic substances in the first step and in the second step, removing organophosphates from the body with hemoperfusion with coal particles. In the previous studies, it was shown that intravenous lipid emulsion treatment increased lethal dose threshold, especially in toxicity caused by anesthetics with lipophilic properties, and reduced mortality (29).

In contrast to poisoning with lipophilic drugs, there are few studies investigating the effects of ILE treatment in OP poisonings. Tuzcu et al (16) reported that oral lipid emulsion treatment might have therapeutic effects on pancreatic tissue in low dose organophosphate poisoning. In parallel to the results of this study, Basarlan et al (15) reported that in organophosphate toxicity, early oral lipid emulsion therapy had an apparent therapeutic effect on brain tissue. They emphasized that lipid emulsion therapy should not be avoided as a safe treatment in such poisonings. According to Dunn et al (30), the timing of the infusion significantly affects the effectiveness of ILE and therefore, the timing of lipid infusion should be adjusted according to the peak concentration of the toxic substance. In our study, ILE infusion was applied $10 \mathrm{~min}$ after malathion that this timing of ILE administration could significantly reverse the histological injury of the liver tissue. Additionally, we found a decrease in the apoptosis after treatment with ILE and this may have been caused by ILE binding to malathion and reduction of the free malathion levels in circulation.

\section{Conclusions}

In this study, we experimentally conducted, it can be said that in organophosphate intoxication, the ILE therapy that had a therapeutic effect on the liver tissue. A decrease in apoptotic activity can be interpreted that the ILE therapy binds malathion and prevents it from accessing to the liver parenchyma, and thereby reduces the amount of malathion that would be metabolized in the first place. This effect of ILE might be caused, beside lipid sink theory, by a large amount of energy production via intact mitochondria from fatty acids with high energies and protection of the cells. In order to make this distinction, it is needed to show in vitro environment, how much it binds lipid organophosphates. Since our study examined only early effects of the ILE therapy, further comparative studies to show its early, mid and late effects are required.

\section{References}

1. Klein-Schwartz W, Smith GS. Agricultural and horticultural chemical poisonings: mortality and morbidity in the United States. Ann Emerg Med 1997; 29: 232-238.

2. Liu SH, Lin JL, Weng CH, Yang HY, Hsu CW, Chen KH et al. Heart rate-corrected QT interval helps predict mortality after intentional organophosphate poisoning. PLoS One 2012; 7: e36576.

3. Antonijevic B, Stojiljkovic MP. Unequal efficacy of pyridinium oximes in acute organophosphate poisoning. Clin Med Res 2007; 5: 71-82.

4. Munidasa UA, Gawarammana IB, Kularatne SA, Kumarasiri PV, Goonasekera CD. Survival pattern in patients with acute organophosphate poisoning receiving intensive care. J Toxicol Clin Toxicol 2004; 42: 343-347.
5. Rothschild L, Bern S, Oswald S, Weinberg G. Intravenous lipid emulsion in clinical toxicology. Scand J Trauma Resusc Emerg Med 2010; 18: 51 .

6. Harvey M, Cave G, Prince G, Lahner D. Epinephrine injection in lipid-based resuscitation from bupivacaine-induced cardiac arrest: transient circulatory return in rabbits. Anesth Analg 2010; 111: 791-796.

7. Foxall G, McCahon R, Lamb J, Hardman JG, Bedforth NM. Levobupivacaine-induced seizures and cardiovascular collapse treated with Intralipid. Anaesthesia 2007; 62: 516-518.

8. Hsiao CT, Yang CC, Deng JF, Bullard MJ, Liaw SJ. Acute pancreatitis following organophosphate intoxication. J Toxicol Clin Toxicol 1996; 34: 343-347.

9. Lukaszewicz-Hussain A. Subchronic intoxication with chlorfenvinphos, an organophosphate insecticide, affects rat brain antioxidative enzymes and glutathione level. Food Chem Toxicol 2008; 46: 82-86.

10. Singh RN. Effects of dimethoate ( $30 \% \mathrm{EC})$, an organophosphate pesticide on liver of common carp, Cyprinus carpio. J Environ Biol 2014; 34: 657-661.

11. Mishra V, Srivastava N. Organophosphate pesticides-induced changes in the redox status of rat tissues and protective effects of antioxidant vitamins. Environ Toxicol 2015; 30: 472-482.

12. Ojha A, Srivastava N. Redox imbalance in rat tissues exposed with organophosphate pesticides and therapeutic potential of antioxidant vitamins. Ecotoxicol Environ Saf 2012; 75: 230-241.

13. Von Der Wellen J, Worek F, Thiermann H, Wille T. Investigations of kinetic interactions between lipid emulsions, hydroxyethyl starch or dextran and organophosphorus compounds. Clin Toxicol 2013; 51: 918922 .

14. Zhou Y, Zhan C, Li Y, Zhong Q, Pan H, Yang G. Intravenous lipid emulsions combine extracorporeal blood purification: a novel therapeutic strategy for severe organophosphate poisoning. Med Hypotheses 2010; 74: 309-311.

15. Basarslan SK, Alp H, Senol S, Evliyaoglu O, Ozkan U. Is intralipid fat emulsion a promising therapeutic strategy on neurotoxicity induced by malathion in rats? Eur Rev Med Pharmacol Sci 2014; 18: 471-476.

16. Tuzcu K, Alp H, Ozgur T, Karcioglu M, Davarci I, Evliyaoglu $O$ et al. Oral intralipid emulsion use: a novel therapeutic approach to pancreatic beta-cell injury caused by malathion toxicity in rats. Drug and chemical toxicology 2014; 37: 261-267.

17. Ozsoy AZ, Nursal AF, Karsli MF, Uysal M, Alici O, Butun I et al. Protective effect of intravenous lipid emulsion treatment on malathioninduced ovarian toxicity in female rats. Eur Rev Med Pharmacol Sci 2016; 20: 2425-2434.

18. McCloy RA, Rogers S, Caldon CE, Lorca T, Castro A, Burgess A. Partial inhibition of Cdk1 in G 2 phase overrides the SAC and decouples mitotic events. Cell cycle 2014; 13: 1400-1412.

19. Ortak H, Cayli S, Ocakli S, Söğüt E, Ekici F, Tas U et al. Age-related changes of aquaporin expression patterns in the postnatal rat retina. Acta Histochem 2012; 115: 382-388.

20. Fortunato JJ, Feier G, Vitali AM, Petronilho FC, Dal-Pizzol F, Quevedo J. Malathion-induced oxidative stress in rat brain regions. Neurochem Res 2006; 31: 671-678.

21. Muthukumaran S, Sudheer AR, Menon VP, Nalini N. Protective effect of quercetin on nicotine-induced prooxidant and antioxidant imbalance and DNA damage in Wistar rats. Toxicology 2008; 243: 207-215. 


\section{3-378}

22. Lu L, Wang X, Lang L, Fu F. Protective effect of reduced glutathione on the liver injury induced by acute omethoate poisoning. Environ Toxicol Pharmacol 2010; 30: 279-283.

23. Karami-Mohajeri S, Abdollahi M. Toxic influence of organophosphate, carbamate, and organochlorine pesticides on cellular metabolism of lipids, proteins, and carbohydrates: a systematic review. Hum Exp Toxicol 2011; 30: 1119-1140.

24. Tas U, Ogeturk M, Kuloglu T, Sapmaz HI, Kocaman N, Zararsiz I et al. HSP70 immune reactivity and TUNEL positivity in the liver of toluene-inhaled and melatonin-treated rats. Toxicol Ind Health. 2013; 29: 514-522.

25. Kurtulus A, Dodurga Y, Yonguc GN, Sorkun HC, Boz B, Acar K. Effect of short-term exposure to dichlorvos on rat hepatocyte: molecular and histopathological approach. Rom J Leg Med 2012; 20: 155-160.
26. Bajgar J, Fusek J, Kuca K, Bartosova L, Jun D. Treatment of organophosphate intoxication using cholinesterase reactivators: facts and fiction. Mini Rev Med Chem 2007; 7: 461-466.

27. Karami-Mohajeri S, Abdollahi M. Mitochondrial dysfunction and organophosphorus compounds. Toxicol Appl Pharmacol 2013; 270: 39-44.

28. Nordenstrom J, Carpentier YA, Askanazi K, Robin AP, Elwyn DH, Hensle TW et al. Metabolic utilization of intravenous fat emulsion during total parenteral nutrition. Ann Surg 1982; 196: 221-231.

29. Ludot H, Tharin JY, Belouadah M, Mazoit JX, Malinovsky JM. Successful resuscitation after ropivacaine and lidocaine-induced ventricular arrhythmia following posterior lumbar plexus block in a child. Anesth Analg 2008; 106: 1572-1574.

30. Dunn C, Bird SB, Gaspari R. Intralipid fat emulsion decreases respiratory failure in a rat model of parathion exposure. Acad Emerg Med 2012; 19: 504-509.

Received February 19, 2018. Accepted March 12, 2018. 